\title{
O Uso Político da Religião e o Uso Religioso da Política: Como a Defesa de Pautas Morais Indica uma Compreensão de Gênero
}

\author{
The Political Use of Religion and Religious Use of Politics: How the Defense of \\ MORAL GUIDELINES INDICATES A COMPREHENSION OF GENDER
}

ANA LUISA GouvÊA Neto*

\begin{abstract}
RESUMO
O presente texto abordará a relação entre religião e política, tão debatida na atualidade brasileira. Pretende-se identificar qual a perspectiva de gênero projetada pela Frente Parlamentar Evangélica a partir das pautas morais que a unem, sobretudo, às pautas ligadas à sexualidade e ao movimento LGBT. Nessas páginas, a relação entre política e religião abarcará apenas o estrato evangélico, sobretudo o pentecostal, da sociedade brasileira. Para tanto, o trabalho será dividido em três partes: no primeiro momento será apresentada a reconfiguração do campo religioso brasileiro a partir da expansão dos evangélicos no país; no segundo momento abordará a inserção evangélica na política, concomitante ao período de redemocratização do país; e no terceiro momento, será trabalhada a Frente Parlamentar Evangélica, desde seu Estatuto.
\end{abstract}

PALAVRAS-Chave: Frente Parlamentar Evangélica. Sexualidade. Gênero.

\section{ABSTRACT}

This paper will address the relationship between religion and politics, as discussed in Brazil today. It is intended to identify the gender perspective projected by the Evangelical Parliamentary Front based on the moral agendas that unite above all the guidelines related to sexuality and the LGBT movement. In these pages the relationship between politics and religion will cover only the Evangelical stratum, especially the Pentecostal, of Brazilian society. The work will be divided into three parts: in the first moment will be presented the reconfiguration of the Brazilian religious field starting with the expansion of evangelicals in the country; in the second moment it will be addressed the evangelical inclusion in politics, concurrent with the redemocratization period of the country; in the third moment will be crafted the Evangelical Parliamentary Front, from their Statute.

KEYWORDS: Evangelical Parliamentary Front. Sexuality. Gender.

\section{RECONFIGURAÇÃO DO CAMPO RELIGIOSO BRASILEIRO}

Acompanhando as mudanças ocorridas no país ao longo do século XX, o movimento evangélico também sofre transformações, tanto estruturais, quanto teológicas. O apoliticismo, as restrições ao mundano e o comportamento asceta aos poucos vão perdendo força no meio evangélico, que passa a se adaptar ao novo contexto histórico-social ${ }^{1}$.

\footnotetext{
* Graduada em História pela UFJF e Mestrado em Ciência da Religião pelo PPCIR-UFJF, Atualmente é doutoranda do PPCIR-UFJF com atuação na Diretora de Divulgação da ABHR (2016-2019). Bolsista Capes. E-mail: analu172@hotmail.com

${ }^{1}$ A partir da democratização, da abertura para o mercado econômico liberal, há uma transformação de mentalidade do cidadão. A democracia trouxe consigo valores ligados à liberdade de escolha. Somada à nova capacidade de consumo possibilitada a partir da nova política economia, o cidadão de forma geral - e sobretudo a classe média - ganha poder de compra. Há toda uma transformação na construção do cidadão, agora com a mentalidade consumidora. O movimento pentecostal vai acompanhar essa transformação na sociedade e se adaptar a esses novos valores e mentalidades.
} 
Com a transformação do movimento evangélico, há uma inserção em novos estratos e grupos sociais, ampliando de forma ainda maior a sua força e participação na sociedade.

O ser evangélico, na atualidade, se transformou em um fenômeno global. É notável a grande expansão do movimento ao longo das últimas décadas em sociedades emergentes do Pacífico Sul, da África, Leste e Sudeste da Ásia. Mariano (1999, p. 9) trata esse processo como globalização do protestantismo popular. Contudo, a região do mundo em que se verifica a maior expansão evangélica é a América Latina. Para além, o Brasil assume papel preponderante nesse contexto, ao possuir o maior número de protestantes da Latino-América. Dessa forma, tem-se que o maior país católico é também o maior país protestante da América do Sul (MARIANO, 1999, p. 9).

Pentecostais e protestantes históricos compõem o grupo denominado de evangélico na Latino-América. Descendentes da Reforma Protestante ocorrida no século XVI, os evangélicos abarcam igrejas como a Luterana, a Batista e a Metodista, até a Congregação Cristã no Brasil, a Assembleia de Deus e a Universal do Reino de Deus. É essa a religião que mais cresce no país ao longo do século XX, transformando a composição no interior do campo religioso brasileiro (CAMPOS, 2008, p. 15).

Freston propõe a década de 1940 como período para a explosão evangélica, sobretudo de pentecostais, no país (FRESTON, 1993, p. 31). As décadas de 1940/50 foram marcadas por grandes transformações. Houve um alto estímulo industrial em decorrência da II Guerra Mundial, implantou-se a TV no Brasil e aumentaram-se as produções de aparelhos de rádio. No contexto social, o Brasil passou por mudanças: ocorreu um aumento das taxas de natalidade, da migração e das acentuadas desigualdades sociais. O desequilíbrio era grave, e, com a alta taxa de migração, as cidades litorâneas passaram a ficar superpovoadas enquanto o campo e o interior ficaram desocupados; foi necessária a intervenção do Estado para estabelecer uma política de migração (GOMES, 1999).

Caracterizado como movimento de minorias, pobres, analfabetos e negros (MARIANO, 2012, p. 11-12), o pentecostalismo implantado no Brasil, na década de 1910, é bem diferente do encontrado atualmente. Características marcantes como sectarismo, ascetismo, apoliticismo, não são as principais características dos pentecostais na atualidade. Pressupõe-se uma passagem da visão pré-milenarista para pós-milenarista nos redutos pentecostais. Ao ter sua concepção escatológica e teológica mudadas, os pentecostais passam a construir novas identidades, estas agora mais em consonância com o mundo.

A transformação na mentalidade evangélica se dá em todas as esferas do segmento, logo, não é incomum notar igrejas pentecostais conservadoras ou mesmo 
protestantes históricas assumindo características mais modernas e contemporâneas. A transformação da identidade evangélica acompanha a história política, econômica, cultural e social do Brasil. Como dito anteriormente, as décadas de 1940/1950 são preponderantes para esse processo.

A reconfiguração do campo religioso brasileiro muito se deve aos fatores supracitados que possibilitaram a expansão e transformação da mentalidade não somente do pentecostalismo, mas dos evangélicos, levando-os para novos espaços da sociedade. Os evangélicos deixaram de ser minoria perseguida e ocuparam lugares na política, na mídia, na educação, enfim, na sociedade de maneira geral.

\subsection{O EVANGÉLICO ENQUANTO IDENTIDADE}

Ao abarcar diversos tipos de protestantismo, é importante marcar a diferença dentro do campo evangélico. É necessário esclarecer que, ao se tratar de pentecostalismo, o que está em voga é o movimento com raízes no metodismo wesleyano e no movimento holiness. O pentecostalismo se distinguiu do protestantismo histórico ao pregar com base no episódio de Pentecostes: o Espírito Santo se manifesta aos apóstolos através das línguas de fogo. A glossolalia e a cura são os dons do Espírito que se sobressaem no meio pentecostal.

Os pentecostais, diferentemente dos protestantes históricos, acreditam que Deus, por intermédio do Espírito Santo e em nome de Cristo, continua a agir hoje da mesma forma que no cristianismo primitivo, curando enfermos, expulsando demônios, distribuindo bênçãos e dons espirituais, realizando milagres, dialogando com seus servos, concedendo infinitas amostras concretas de Seu supremo poder e inigualável bondade (MARIANO, 2012, p. 10).

O ano de 1980 inaugura um novo padrão de classificação adotado pelo IBGE, com a separação entre protestantes históricos e pentecostais. Nessa época, os protestantes históricos ainda compunham a maior parte da parcela evangélica brasileira, representando $51 \%$ do total.

No entanto, na PNAD de 1988 essa classificação não é mantida, mas o Censo Demográfico de 1991 constata o crescimento acentuado pentecostal representando 65,1\% dos evangélicos.

De acordo com os Censos Demográficos do IBGE em 1980, o percentual de evangélicos comparado à população era de 6,6\%, chegando a 9\% em 1991. Percebe-se que foi na primeira década de 2000 que houve um grande salto da população evangélica, atingindo o número de 26.452.174 adeptos, o que representou $15,6 \%$ da população. O Censo de 2010 mostrou o crescimento contínuo dos evangélicos, 
apontando o número de 42.275.440 adeptos. Isso significa dizer que entre os anos de 2000 e 2010 a população evangélica cresceu 61, 45\%.

Entretanto, devem-se observar dois pontos:

1 - o crescimento evangélico vem ocorrendo de forma desigual no território brasileiro. Destacam-se as regiões Norte e Centro-Oeste como as que mais têm tido adesão ao segmento. Vale salientar que na atual legislatura nenhum estado do Centro-Oeste elegeu uma deputada evangélica;

2 - o crescimento tem acontecido, sobretudo, nos segmentos pentecostais e neopentecostais, salvo os batistas, os protestantes históricos e protestantes de missão, que não parecem demonstrar adesão considerável.

Apesar da distinção dentro do campo protestante - protestantes históricos, protestantes de missão, pentecostais, neopentecostais - observa-se atualmente um movimento de coesão no que diz respeito à identidade evangélica. De acordo com Mariz e Graciano Jr (2013), o Censo Demográfico de 2010 traz uma nova inquietação para os pesquisadores: o aumento do número de pessoas que se declararam evangélicos genéricos. Quer dizer, tais pessoas não estão utilizando o pertencimento denominacional para classificar seu pertencimento religioso. Debates à parte, acionar a identidade evangélica tem trazido consequências para o debate público, no qual os evangélicos têm tido grande visibilidade, sobretudo por sua expansão em números absolutos a partir da década de 1980 e sua inserção na mídia e na política.

Sant'Anna (2014) aborda a Marcha para Jesus enquanto evento que serviria de exemplo dessa nova identidade evangélica, que vem sendo acionada em favor de uma coesão identitária religiosa. A partir de seu texto pode-se notar que a Marcha é a ocupação do espaço urbano feita por uma coalizão formada por diferentes denominações. $\mathrm{E}$, ainda que seja heterogênea, no que diz respeito a doutrinas e teologias, no intuito de evangelizar em nome de Jesus, faz uso de uma identidade evangélica que tem a capacidade de unir, na diferença.

Não obstante, verifica-se um movimento político desde as eleições para Constituinte, no ano de 1985, em consonância com essa nova identidade unificadora. Ou seja, tem havido um movimento de flexibilização entre as fronteiras de diferentes denominações religiosas e a construção de um campo de atuação - político, midiático - em comum, que pretende falar pelos evangélicos. E produções privilegiadas, na política e na mídia, conseguem passar essa ideia de unificação do campo evangélico, tal como a Marcha para Jesus, que de acordo com Sant'Anna (2014) pode ser considerada como evento chave na formação do ethos evangélico transdenominacional.

\section{INSERÇÃO EVANGÉLICA NO DEBATE PÚBLICO}


As relações políticas, culturais e religiosas exibem a identidade evangélica enquanto é construída pela mídia - impressa, eletrônica e audiovisual. Para Belotti, "No caso da cultura evangélica, observamos a tendência da religiosidade autônoma, em que os indivíduos dispõem do mercado cultural para formar visões de mundo, afirmar ou questionar sua identidade" (BELLOTTI, 2010, p. 57).

Importam aqui as consequências trazidas pela utilização da mídia na atualidade. Até por volta dos anos 1970, os evangélicos limitavam sua ação proselitista midiática ao rádio e aos impressos. Porém, na mesma década, vê-se a consolidação dos hábitos em relação ao uso da televisão e, já em 1980, a produção da TV ocorre de forma massiva, com a entrada dos evangélicos na produção televisiva, o que possibilitou a comunicação em massa nesse segmento religioso.

A partir, sobretudo, da década de 1960 e 1970, o cenário político, econômico e tecnológico do Brasil contribuiu para o desenvolvimento da indústria cultural no país. É nesse novo cenário que a religião encontra um ambiente profícuo para a propagação de suas práticas e costumes. E, de acordo com Freston, "o tamanho do mercado pentecostal justifica uma mídia especializada para este segmento" (FRESTON, 1993, p. 136), uma vez que o seguimento evangélico foi o que mais cresceu no Brasil entre os anos de 1980 e 2000, saltando de 15,6\% da população em 2000 para 22,2\% da população em 2010, o que representa em números absolutos um aumento de 20, 1 milhões de adeptos.

O modelo de mercado fez com que diferenças doutrinárias perdessem força perante uma tendência crescente de enfatizar o lado prático da religião. Por isso, temas como família, moral e a educação infantil ganharam relevo. A família foi considerada pelos evangélicos o bastião de resistência às mudanças socioeconômicas e culturais do século XX. (BELLOTTI, 2010, p. 235).

A partir do discurso de líderes evangélicos - ressalta-se nesse ponto, a heterogeneidade verificada no setor, e consequentemente, as diferentes práticas, discursos e condutas - a ideia de se defender os valores cristãos - morais e éticos são trazidos para a esfera pública através dos meios de comunicação e chegam a repercutir na política brasileira. A lembrar da troca de visões pré-milenaristas, individualizadas, para a pós-milenarista, em busca da coletividade em forma de sociedade ética, moral, sem sofrimentos e, sobretudo, próspera. Os evangélicos, ao mudar a ênfase da mensagem religiosa e, com o auxílio dos meios de comunicação, ao legitimarem um novo modelo de vida, reconfiguram a imagem que o fiel tem de si e de seu grupo, forjando uma nova identidade evangélica. A entrada dos evangélicos, a 
destacar os pentecostais e neopentecostais, na esfera política, não salta aos olhos, haja vista a nova configuração da identidade evangélica.

\subsection{IRMÃO VOTA EM IRMÃO: A INSERÇÃO EVANGÉLICA NA POLÍTICA}

O Batismo no Espírito Santo e os dons do carisma - glossolalia, cura - não são mais as únicas pautas do ser evangélico. Nessa altura do movimento, depois de tantas transformações, rupturas e continuidades, interessa também o poder político. A indústria de comunicação possibilitou aos evangélicos legitimar a nova teologia, na qual a prosperidade é requisito, mas também construir e consolidar uma nova identidade supradenominacional, na qual os políticos evangélicos ou evangélicos políticos a acionam em nome de uma maioria moral, silenciosa (TADVALD, 2015).

A transformação dos valores evangélicos mudou o modo de agir e pensar, reformulando identidades. A imagem do crente ascético, apolítico e sectário não combina mais com o discurso de uma instituição mais moderna e adepta às tecnologias e sociedade e, a velha máxima de que "crente não se mete na política" cedeu lugar para "irmão vota em irmão". O mundo continua condenado, e é função do crente transformá-lo em um paraíso na Terra. A Teologia da Prosperidade e a Guerra contra o Diabo ajudam a legitimar a participação das lideranças evangélicas na arena política.

Se antes condenavam a Igreja Católica pela sua aproximação com o Estado na busca de aquisição de privilégios, agora, buscam as mesmas benesses ${ }^{2}$. Condenar o mundo não leva mais o crente a se tornar sectário, pelo contrário, o traz para lutar no presente em busca de fazer a diferença no mundo. O parlamento se torna o lugar central de disputas e lutas para implantação de valores morais cristãos na sociedade. A batalha, antes mística, a partir da inserção dos evangélicos na política, se torna física. Cabem aos representantes religiosos lutarem a partir de projetos e conchavos políticos para tornar o Brasil o Paraíso Terrestre.

\subsection{NOVOS RUMOS COM A REDEMOCRATIZAÇÃO}

A visibilidade dos evangélicos brasileiros na esfera política ocorre no período préeleitoral de 19863. O discurso do momento girava em torno da Constituinte, que daria reais possibilidades para que se reescrevesse o Brasil. Era a oportunidade que o evangélico tinha para mostrar superado o complexo de minoria - apesar de utilizar

\footnotetext{
2 Tais benesses dizem respeito ao relacionamento de tais igrejas com o poder público, tendo facilitadas concessões de emissoras de TV e rádio, por exemplo.

3 Tendo em vista que Freston (1993) aponta que em 1930 já se podia encontrar parlamentares evangélicos, entretanto esses eram pouco e advindos de Igrejas Protestantes Históricas.
} 
esse discurso em período eleitoral - e ter voz política ativa. A República traz consigo uma reconfiguração do interesse de atuação política dentro do setor evangélico.

Esse novo interesse nasce da necessidade de ter representatividade na Assembleia Constituinte, que foi conseguida através da eleição de 34 parlamentares que se autodeclararam evangélicos. De acordo com Pierucci (1989, p. 104) tais evangélicos se propuseram a coordenar suas ações para a pauta moral em confluência com a direita política, em busca de publicidade e visibilidade. $\mathrm{O}$ autor defende a ideia de uma "nova direita cristã" articulada para agir a favor dos costumes tradicionais e da moral sexual cristã. Já nesse momento puderam-se identificar tensões entre a defesa de uma pauta moral cristã e o feminismo - o qual possibilitaria o rompimento da hierarquia patriarcal pautada na diferenciação sexual biológica -, a sexualidade, questões ligadas à homossexualidade, entre outras.

Entre as 24 subcomissões criadas para a elaboração do primeiro texto, os evangélicos estiveram presentes em 16. Entretanto, tiveram especial cuidado em se concentrar na Comissão da Família, Educação e Cultura, na qual 12 parlamentares evangélicos marcaram presença. "A Folha noticiava 'um novo lobby no Congresso Constituinte" (PIERRUCCI, 1989, p. 124), assim, a visibilidade fez com que as igrejas evangélicas virassem notícia, não somente na mídia religiosa, mas também na mídia secular.

Vale ressaltar que desde o primeiro momento a Igreja Assembleia de Deus, com sua característica marcante de apoliticismo, logo percebe a importância de se fazer representar na esfera pública política nacional. Um exemplo pode ser dado a partir da Convenção Geral de 1985, realizada em Goiás, na qual líderes tecem comentários sobre a importância da Constituinte. O lema inaugurado é o da oração mais ação - a ação do crente sob forma de voto.

A nova mobilização se reflete na indicação de candidatos apoiados pela própria igreja na tentativa de se perder a menor quantidade possível de votos. O resultado foi positivo, e a Assembleia de Deus conseguiu eleger 13 deputados; e nas eleições de 2002, já eram 22 deputados ligados à Assembleia de Deus (ROCHA, 2009, p. 81). Entretanto, essa entrada na corrida política não ocorreu por parte de todas as igrejas evangélicas; a Congregação Cristã do Brasil e a Deus é Amor ainda se mantêm à parte da corrida eleitoral. A representação evangélica na Câmara dos Deputados entre 1987 e 1990 encontra-se na tabela abaixo:

\begin{tabular}{|c|c|}
\hline \multicolumn{2}{|c|}{$1987-1990$} \\
\hline Igrejas Pentecostais & $\mathrm{N}^{\circ}$ de Parlamentares \\
\hline Assembleia de Deus & 13 \\
\hline Evangelho Quadrangular & 2 \\
\hline
\end{tabular}




\begin{tabular}{|l|c|} 
Igreja de Cristo & 1 \\
\hline Universal do reino de Deus & 1 \\
\hline Batista Nacional & 1 \\
\hline \multicolumn{2}{|c|}{ Igrejas Históricas } \\
\hline Batista & 7 \\
\hline Presbiteriana do Brasil & 2 \\
\hline Presbiteriana Independente & 1 \\
\hline Presbiteriana Unida & 1 \\
\hline Cristã Reformada & 1 \\
\hline Congregacional & 1 \\
\hline Cristã Evangélica & 1 \\
\hline Adventista & 1 \\
\hline
\end{tabular}

Figura 1. Igrejas representadas na Assembleia Constituinte.

A tabela acima evidencia que desde a Constituinte de 1986 a participação evangélica é maior no segmento pentecostal e neopentecostal, se comparado ao segmento do protestantismo histórico. Salienta-se que atualmente, juntamente com a Assembleia de Deus e a Batista, a Universal do Reino de Deus é uma das igrejas que mais elege seus candidatos.

A partir do modelo instaurado pela Igreja Universal do Reino de Deus (IURD) desde as eleições constituintes de 1986, as igrejas que obtêm maior sucesso nesta arena são aquelas que possuem projetos mais bem definidos de inserção na política e que utilizam seus templos e demais espaços religiosos, incluindo os virtuais, para fazer campanha para seus candidatos, dispondo de profusos meios materiais e midiáticos que contribuem na difusão das campanhas entre os seus fiéis e até para além deles. (TADVALD, 2015, p. 260).

O pontapé na corrida política foi dado pela Assembleia de Deus, a qual ainda consegue eleger inúmeros candidatos; mas, até as eleições de 2010, a igreja que mais elegeu governantes foi a Universal do Reino de Deus: a "Universal inaugurou um novo estilo de fazer política nas igrejas, trata-se de um específico corporativismo de viés religioso" (ROCHA, 2009, p. 83). Após a redemocratização do país, assiste-se a uma política evangélica dominada por políticos ligados ao pentecostalismo clássico. Já nos fins da década de 1990, vê-se a neopentecostalização da Frente Parlamentar Evangélica.

Para facilitar a conquista de votos, as igrejas evangélicas têm se empenhado em lançar candidatos próprios, influentes e conhecidos no ambiente institucional religioso. Membros da hierarquia são lançados como candidatos na busca de transferir a influência religiosa para a esfera política. Entretanto, nem todas as igrejas obedecem às mesmas estratégias políticas inauguradas pela IURD: um exemplo seria a pulverização dos votos ocorrida nas eleições de 2014 no Rio Grande 
do Sul, de candidatos ligados à Igreja Assembleia de Deus (ORO; CARVALHO JÚNIOR, 2010, p. 165).

\subsection{IMBRICAÇÕES ENTRE RELIGIÃO E POLÍTICA NO BRASIL}

No Brasil atual, religião e política são esferas que conversam entre si. Com a explosão evangélica no debate público, muito se tem falado, no processo histórico da secularização. Veem-se no Congresso embates constantes entre discursos a favor do secular - superior à religião, neutro de valores religiosos - e discursos a favor do direito que a religião teria em se expressar de forma política. Campos aponta para tensões e conflitos gerados a partir da participação religiosa no cenário público (CAMPOS; et. al., 2015). Tais conflitos e tensões tornam-se notórios com a entrada do segmento evangélico na política, que apesar de constituir minoria comparada à população, ocupa lugar de grande visibilidade.

As imbricações entre religião e política no Brasil podem ser compreendidas em duas esferas: em um plano, tem-se o uso político da religião; e no outro plano, tem-se o uso religioso da política. As existências dessas duas esferas não se excluem; pelo contrário, se complementam e, em momentos de eleições, por exemplo, é possível delinear fronteiras entre essas esferas.

Os principais atores a acionarem as esferas que relacionam religião/política são os evangélicos. Boa parte dos candidatos que se autodeclaram religiosos é proveniente do segmento evangélico, com destaque para os pentecostais e neopentecostais. Sendo assim, é praticamente impossível pensar em política no Brasil sem levar em consideração o campo religioso evangélico.

A participação evangélica na política esteve sempre em ascensão, salvo o ano de 2006, ano no qual a Igreja Universal do Reino de Deus freou a indicação de candidatos oficiais por consequência de escândalos políticos. Nesse ponto cabe destacar a associação entre evangélicos e escândalos políticos envolvendo corrupção, fisiologismo presente desde a Constituinte de 1986. Sendo assim, o ano de 2006 pode ser visto como de uma crise eleitoral evangélica. Entretanto, o ano de 2010 aponta para a recuperação eleitoral evangélica, e o ano de 2014 assinala a consolidação e até mesmo a expansão do campo evangélico na política.

O sucesso do projeto político evangélico se deve a três fatores. O primeiro, a proximidade que a igreja tem com o fiel, como também as influências que a mesma exerce na vida desse fiel. Com uma pauta voltada para a família e a moral cristã, o segmento conseguiu legitimar sua presença na arena política e remodelar a identidade de seus membros. O segundo fator está ligado à estruturação. Nas igrejas, por serem estruturadas de forma centralizada e oligárquica, seus dirigentes tomam as 
decisões e as transmitem para os fiéis. Nas lideranças assembleianas, por exemplo, há um forte caráter caudilhesco e coronelístico. O terceiro e último fator, mas não menos importante, relaciona-se com a eficiência das igrejas na utilização dos meios de comunicação em massa. De acordo com Freston (1993), política e mídia se reforçam reciprocamente na composição do campo evangélico. Não é de se espantar ver famosos da mídia evangélica compondo a Frente Parlamentar Evangélica.

O segmento evangélico brasileiro saiu, em um século, de uma posição de à margem da sociedade para o centro. Vê-se com o passar dos anos as transformações ocorridas no interior do campo e a consequente transformação do ser evangélico. $\mathrm{O}$ sectarismo, apoliticismo, pré-milenarismo, se não suplantados, são diminuídos em meio às constantes adaptações das igrejas à modernidade. Hoje, os evangélicos reconhecem sua força e se utilizam da mídia e da política para reclamar seus direitos e suas demandas religiosas sempre a favor dos interesses corporativos, políticos e econômicos de suas instituições.

\subsection{A COESÃo EVANGÉLICA}

Já se mencionou que os parlamentares evangélicos, desde a Assembleia Constituinte de 1986, têm formado um bloco suprapartidário e supradenominacional, o qual se convencionou ser chamado de Bancada Evangélica, composto em sua maioria por parlamentares evangélicos com posturas conservadoras e tradicionais, e por isso, denominado por Pierucci (1989, p. 124) de "Nova Direita Cristã".

Isso significa dizer que nas votações do Congresso esse bloco evangélico tem uma tendência a votar em consonância com os partidos considerados de direita. Para além, e aqui se centra o mote desse bloco, a politização evangélica no Brasil traz para o debate político questões relacionadas aos valores tradicionais e moralistas da sociedade cristã.

Em nome de uma maioria moral cristã - pois o Brasil é um país predominantemente de matriz cristã -, os representantes evangélicos preponderantemente conservadores e tradicionalistas buscaram, desde 1986, consolidar uma imagem de bloco coeso, através de uma identidade unificada que rompe com as fronteiras das denominações religiosas.

A coesão dos parlamentares evangélicos se deve às suas pautas, que se unem em torno dos bons costumes, da moral sexual evangélica, da família cristã. Pontos de divergências, tais como os que abarcam questões sociais, são relegados ao segundo plano. Entretanto, não se pode assumir que todos os parlamentares evangélicos têm posturas conservadoras e tradicionalistas. Assim como o próprio segmento 
evangélico, que é composto por diversas denominações, com doutrinas, teologias e costumes distintos, também o são os parlamentares.

Todavia, se o grupo que se tem por costume denominar de evangélico guarda heterogeneidade, não significa que todas as diferenças ocupem lugar de mesma visibilidade que as correspondências. De acordo com Sant'Ana (2014, p. 213) a identidade evangélica, enquanto englobante, pode ser acionada, pois ao contrário do que se espera, não é livre de assimetrias, mas produzida por metonímias, nas quais grupos e lideranças que se destacam na indústria cultural e na política parlamentar são apresentados como totalidade a partir das posições de prestígio que ocupam.

Destarte, são essas lideranças e grupos auxiliados pela mídia e pela política partidária que criam, reproduzem e representam a identidade evangélica para além das denominações. E assim, o conservadorismo moral enquanto pauta política, também se faz presente em parte do eleitorado, pois é justamente a questão moral que tem tido centralidade e peso na definição do voto cristão evangélico (SOUZA, 2013, p. 184).

\section{A Frente Parlamentar Evangélica E A PERSPECTIVA DE GÊNERO}

O Estatuto da Frente Parlamentar Evangélica traz em seu artigo $2^{\circ}$. III:

Procurar, de modo contínuo, a inovação da legislação necessária à promoção de políticas públicas, sociais e econômicas eficazes, influindo no processo legislativo a partir das comissões temáticas existentes nas Casas do Congresso Nacional, segundo seus objetivos, combinados com os propósitos de Deus, e conforme Sua Palavra. (BRASIL, 2016, p. 4).

Como visto no trecho acima, a Frente Parlamentar Evangélica tem por objetivo legislar em nome de Deus. De acordo com Machado, ao realizar entrevistas com evangélicos ligados de alguma forma à política, “[...] é necessário atuar na qualificação dos pentecostais, formar cidadãos mais ativos e uma liderança política que possa ocupar os espaços do poder, propor leis e políticas públicas condizentes com o ideário cristão [...]" (MACHADO, 2015, p. 53).

A inserção na política e o ativismo religioso são necessários para enfrentar a situação em que o país se encontra, de ameaça à instituição tradicional da família e a moral e ética cristã. O movimento feminista e o movimento LGBT estariam contribuindo para a destruição da família tradicional cristã, e por isso precisariam ser combatidos.

A citação abaixo faz parte do requerimento de 2015, feito ao presidente da Câmara dos Deputados, Deputado Eduardo Cunha, para registro da Frente Parlamentar Evangélica - F.P.E. (criada em 04 de setembro de 2003): 
Requeiro nos termos do artigo 15, inciso I e VIII do Regimento da Câmara dos Deputados e do Ato da Mesa $n^{0}$ 69, de 10 de novembro de 2005, o registro da Frente

Parlamentar Evangélica do Congresso Nacional que reúne Deputados Federais e Senadores preocupados em fiscalizar os programas e as políticas governamentais, voltados à proteção da família, da vida humana e dos excluídos e acompanhar a execução das mesmas, bem como participar do aperfeiçoamento da legislação brasileira no interesse da sociedade e ainda do debate dos grandes temas nacionais (BRASIL, 2016, p. 1).

A F.P.E. surge como consequência da transformação da mentalidade relacionada à política, a partir da inserção dos evangélicos no cenário político na busca de defesa de seus interesses religiosos, políticos, econômicos, institucionais. A mobilização parlamentar e extraparlamentar evangélica em torno de uma coalizão fez com que os evangélicos agissem de forma alinhada desde a Assembleia Constituinte de 1986, e a F.P.E. nasce como uma forma legítima de representação dos evangélicos no espaço político.

Composta por Deputados Federais, Senadores e por colaboradores - ex parlamentares - que se autodeclaram evangélicos e que acionam suas identidades religiosas enquanto ação política, tal segmento evangélico-parlamentar tem carregado como mote de suas pautas a defesa dos bons costumes, da família e da moral sexual cristã. Em sua grande maioria, os parlamentares que compõem a F.P.E. são filiados aos partidos considerados de direita e de caráter conservador.

De acordo com Souza (2015, p. 263), a Frente tem apresentado uma média de participação feminina superior à participação na Câmara dos Deputados; todavia, nas próprias comissões criadas pela F.P.E., na presidência da mesma, e quando se trata de indicação de políticos pelos partidos vinculados ao segmento, os homens são destacados. Não obstante, a Bancada Evangélica, como usualmente é chamada, tem sido o segmento que tem se posicionado de maneira fortemente contrária aos direitos LGBTs, sexuais, reprodutivos e a "ideologia de gênero".

A matéria intitulada Deputados evangélicos radicalizam contra união de homossexuais na Aleac, publicada pela A Gazeta do Acre (2016); a matéria Projeto de lei poderá criar o "bolsa-estupro" para evitar que mulheres abortem, publicada pelo Correio24horas (2016) e a notícia publicada no site do Senador Magno Malta, Cristãos criam força-tarefa para combater ideologia de gênero nas escolas (MALTA, 2016), são alguns exemplos da forma com a qual a Frente Parlamentar Evangélica vem lidando com projetos de lei que visam ampliar os direitos do segmento LGBT, direitos reprodutivos femininos e direitos que estejam ligados às questões relacionadas a gênero. Além de atuarem como fortes opositores de tais projetos de lei, em muitas ocasiões elaboram ou defendem projetos que têm por objetivo retroceder direitos já adquiridos, ou mesmo que inviabilizem a ampliação 
dos direitos mencionados anteriormente. Há que se perguntar, no entanto, o porquê desse combate militante à "ideologia de gênero". Com base nas pautas que unem os parlamentares evangélicos, se pretende identificar qual a perspectiva de gênero projetada pela Frente Parlamentar Evangélica.

Entre as pautas defendidas pela Frente Parlamentar Evangélica, duas serão abordadas: a questão do aborto e os direitos LGBTs. As mesmas assumem lugar de destaque quando o assunto é a defesa da moralidade cristã.

Quando se trata de debater questões relacionadas ao corpo feminino, tal como o aborto, deve-se pensar que nem todas as instituições religiosas abordam o assunto da mesma forma. Os discursos institucionais são heterogêneos, assim como os discursos dos parlamentares que compõem a Frente Parlamentar Evangélica. Há, portanto, uma flexibilização da compreensão por parte de algumas instituições sobre situações possíveis da interrupção da gravidez. Gomes (2008, p. 3) aponta para posturas institucionais mais abertas em relação ao tema. Tais igrejas seriam: a Igreja Presbiteriana do Brasil, a Igreja Metodista e a Igreja Universal do Reino de Deus. Ainda que o posicionamento institucional de algumas igrejas aponte para uma visão mais flexível no debate em torno do aborto, não significa, consequentemente, que os parlamentares ligados a essas instituições irão reproduzir o mesmo discurso. Existe certo grau de autonomia dos parlamentares em relação às suas instituições religiosas.

A dissonância entre parlamentares evangélicos e discursos oficiais de instituições religiosas pode ser exemplificada pelo deputado federal Áureo Lídio Moreira Ribeiro, evangélico metodista, um dos criadores, em 2005, da Frente Parlamentar em Defesa da Vida, que tem por finalidade: "[..] acompanhar e fiscalizar os programas e as políticas públicas governamentais destinadas à proteção e garantia dos direitos à vida, a família, da criança e do adolescente [...]”(BRASIL, 2016b, p.1). Destarte, a Igreja Metodista admite o planejamento familiar, bem como a interrupção da gravidez nos seguintes casos: estupro, risco de morte da mãe e má formação fetal; enquanto a Frente Parlamentar em Defesa da Vida é contrária à legalização do aborto.

Recorrente na pauta da Frente Parlamentar Evangélica, o aborto é tema debatido desde o início da formação da coalizão evangélica no Congresso. Frases como: 'Se uma mulher quiser, ela pode resistir ao estupro [...] Se a mulher não quer, o homem não consegue estuprá-la' (PIERRUCCI, 1969, p. 122), proferidas pelo à época deputado Sotero Cunha, pastor da Assembleia de Deus, enquanto justificativa para a não descriminalização do aborto, dão sinais, não somente, da preocupação em normatizar o corpo feminino, mas também, da compreensão de uma perspectiva de gênero. 
Na mesma linha do deputado-pastor de 1987, em 2007, o parlamentar evangélico Henrique Afonso apresentou o Projeto de Lei 1.763/2007, o qual tinha por objetivo pagar uma "bolsa-auxílio" - equivalente a um salário mínimo, a ser paga pelo Estado, durante 18 anos - às mulheres que tenham sido vítimas de violência sexual e engravidaram durante o ato. O projeto apelidado de "bolsa estupro" foi defendido pelo parlamentar no seguinte argumento: ' $\mathrm{O}$ aborto, para nós, evangélicos, é um ato contra a vida em todos os casos, não importa se a mulher corre risco ou se foi estuprada' (SOUZA, 2013, p. 187). Aqui, percebe-se a utilização da moral cristã e do acionamento da identidade evangélica, enquanto grupo englobante, para justificar sua fala e sua posição.

O tema sexualidade mobiliza os parlamentares religiosos, que buscam através da religião impor à sociedade valores morais. Tão caro às mulheres, sexualidade e feminino sempre foram temas encarados enquanto abjetos pela religião. Os parlamentares evangélicos reproduzem e produzem os discursos institucionais religiosos relacionados à compreensão de gênero que estão ligados a uma interpretação de divisão social do trabalho com base nos sexos, construída pelas instituições. E que ganha característica de natural e eterna. E, por ser natural ganha autoridade para legitimar a própria ordem que constrói. Há uma reprodução dessa ordem que evidencia a força da ordem masculina, a qual dispensa justificação. A sociedade construída a partir da base androcêntrica ratifica de forma simbólica a dominação masculina e a partir dela constrói toda uma divisão social entre os sexos.

Não obstante, a sociedade constrói o corpo como dotado de uma realidade sexuada responsável pela divisão sexual e impõe regras ao corpo, com o objetivo de normatizá-lo. Nos discursos ligados ao debate do aborto, fica claro que os parlamentares evangélicos têm uma compreensão de gênero pautada no binarismo, na qual homens e mulheres têm papéis bem definidos na sociedade, e desiguais. Às mulheres, em uma sociedade pautada por normas androcêntricas, cabe o espaço do privado; enquanto aos homens cabe o espaço do público, e, consequentemente, das discussões em relação à normatização do próprio corpo feminino.

A normatização do corpo, contudo, não é apenas do feminino. A partir do debate que gira em torno das reivindicações do movimento LGBT, também é possível compreender que todos os corpos têm sobre si uma normatização imposta pela sociedade.

No decorrer dos últimos anos assiste-se à ampliação da visibilidade do movimento LGBT no país. Consequentemente, o movimento tem alcançado novos espaços e adquiriu não somente nova força política, mas direitos políticos. Em contrapartida, os parlamentares evangélicos têm se mobilizado na luta contra o segmento LGBT, em prol da moralização da família. Ao tomarem a posição de 
reguladores da sexualidade utilizando o nome de Deus, tais parlamentares vêm travando uma luta político-religiosa no intuito de barrar a ampliação dos direitos LGBT. Um exemplo seria a discussão que suscitou o debate da união civil entre pessoas de igual sexo. Seguindo Duarte,

No Congresso Nacional tramitavam diversos projetos de lei que nunca conquistaram aprovação. Tais projetos foram sistematicamente barrados por representantes da bancada evangélica e também por aqueles que se alinhavam com os interesses da Igreja Católica (SOUZA, 2013, p. 190).

O trecho acima evidencia duas questões: 1) na luta contra os direitos LGBTs, os evangélicos não estão sozinhos: a ala conservadora católica e a Frente Parlamentar Evangélica alinham-se em diversos momentos 4; 2) a "má" vontade do Congresso, no que diz respeito à votação e aprovação de projetos de lei ligados aos direitos LGBTs. A obstacularização é tamanha, que somente em 2011 o Supremo Tribunal Federal decidiu, por unanimidade, reconhecer a união civil entre pessoas do mesmo sexo, garantindo os mesmos direitos que dos casamentos heterossexuais.

Outro debate que ganhou visibilidade envolvendo a bancada evangélica e o movimento LGBT foi a apresentação do Projeto de Lei 234/2011, pelo deputado João Campos - também presidente da Frente Parlamentar Evangélica - apelidado de "cura gay". Aprovado pela Comissão de Direitos Humanos, o projeto foi retirado de pauta por João Campos após as manifestações de 2013. Reapresentado em 2014, contou com forte apoio do deputado Marco Feliciano. Abaixo, algumas frases polêmicas ditas pelo deputado, publicadas no site o Buteco da net (ONEberto, 2013):

- “A AIDS é o câncer gay” (Congresso dos Gideões e Missionários - set. 2012).

- "União homossexual não é normal. O reto não foi feito para ser penetrado. Não haveria condição de dar sequência à nossa raça.” (Revista Veja - 5 mar. 2013).

- "Depois da união civil, virá a adoção de crianças por parceiros gays, a extinção das palavras pai e mãe, a destruição da família.” (Twitter - 20 jan. 2013).

- "Os artistas são a favor do casamento gay; os intelectuais também são. Resta aos cristãos e conservadores de valores morais lutarem.” (Twitter - 20 jan. 2013).

- "A podridão dos sentimentos dos homoafetivos levam ao ódio, ao crime, a rejeição.” (Twitter - 31 mar. 2011).

A imagem do deputado Marco Feliciano materializa, salvo exceções, o posicionamento e o direcionamento da bancada evangélica, nos quais prevalecem o discurso da heteronormatividade e a abjeção dos corpos que não se adequam à matriz de inteligibilidade. Pode-se entender por abjeção, segundo Butler (2002), corpos

\footnotetext{
4 De acordo com Machado (2015), pode-se verificar uma aliança entre os católicos carismáticos e os pentecostais. Ainda que tenham projetos políticos, diferenças doutrinárias distintas, quando se trata da moral sexual e a família, as agendas políticas dos dois segmentos se sobrepõem.
} 
considerados como abjetos ao peso da inaceitabilidade destes por regras de inteligibilidade. Embora tais temas não possuam legitimidade, eles têm significados e são materializados. Corpos abjetos, portanto, são:

[...] todo tipo de corpos cujas vidas não são consideradas 'vidas' e cuja materialidade é entendida como "não importante". [...] Não é o que é impensável, que aquilo que não pode ser vivido ou compreendido não tenha uma vida discursiva; ele certamente a tem. Mas ele vive dentro do discurso como figura absolutamente não questionada, a figura indistinta e sem conteúdo de algo que ainda não se tornou real. (BUTLER, 2002, p. 161-162).

A abjeção dos corpos ocorre dentro de um processo discursivo, no contexto social em que operam relações sociais e poderes com possibilidades de construir significados de acordo com seus interesses. Os corpos, compostos por fronteiras fluidas e por discursos, são capazes de materializar identidades e manifestações de gênero. Ocorre que nem sempre a identidade materializada é aceitável na matriz de inteligibilidade. E é disso que se trata a abjeção, a sinalização de comportamentos e identidades que estão fora do esquema binário em que os sexos/gêneros estão inseridos. Os discursos da Frente Parlamentar Evangélica reforçam uma normatização de ideal de gênero, e tal reforço à materialização de identidades e manifestações de gênero pode ser observado nos discursos reproduzidos por seus integrantes com base conservadora e tradicionalistas ancorados no texto sagrado - a Bíblia.

\section{CONSIDERAÇÕES FINAIS}

O presente texto buscou destacar, ainda que de forma breve, como as pautas morais que unem a Frente Parlamentar Evangélica relacionam-se com a compreensão de gênero pelos parlamentares evangélicos que compõem esse grupo. Para tanto, foi apresentado como esses novos atores entraram no debate público e ganharam visibilidade e poder político.

Viu-se o surgimento de um novo bloco político, coeso em certo sentido, ser formado a partir da redemocratização do país. Os evangélicos, que anteriormente se encontravam à parte da política, enxergaram uma oportunidade de transformarem suas demandas religiosas em demandas políticas a partir das eleições para a Assembleia Constituinte de 1986.

De lá para cá, os evangélicos não só se expandiram em números populacionais, como também fizeram ecoar suas vozes na esfera política. Por meio da eleição de parlamentares evangélicos, as fronteiras entre as denominações religiosas têm se mostrado fluidas e porosas. Com auxílio da mídia e de lideranças políticas, é possível na atualidade se pensar em uma identidade evangélica supradenominacional. Essa 
identidade é acionada constantemente por políticos evangélicos em nome de uma maioria cristã.

Em nome dessa maioria cristã, silenciosa, têm-se visto uma aproximação da Frente Parlamentar Evangélica com a direita conservadora. Projetos de Lei que visam a ampliação dos direitos LGBTs, das mulheres, das minorias de forma geral, têm encontrado dificuldades de aprovação no Congresso brasileiro.

A dificuldade de aprovação de tais projetos relaciona-se às bandeiras empenhadas pela Frente Parlamentar Evangélica. Pautas morais relacionadas à sexualidade, aborto, homossexualidade, etc., são defendidas ferozmente pelos parlamentares evangélicos que se autodefinem como guardiões da moralidade. É no espaço físico, no espaço da política, que a luta entre o Bem e o Mal está sendo travada.

Ao discursarem contra o aborto, contra a união civil entre pessoas de mesmo sexo, a favor da "cura gay", os parlamentares evangélicos indicam com qual perspectiva de gênero estão alinhados: a uma perspectiva estruturalista de gênero, a qual recorre de maneira sistêmica a antagonismos, propondo uma essência universal para o modelo androcêntrico e patriarcal de sociedade.

A partir dos discursos dos parlamentares evangélicos, defende-se aqui que os mesmos entendem os papéis de gênero a partir de um viés estruturalista. Nesse esquema, à mulher, biologicamente fêmea, cabe o espaço do privado, da emoção; e ao homem, biologicamente macho, cabe o espaço do público, da razão. Submetido ao masculino, tal qual natureza/cultura, mente/corpo, o feminino necessitaria da oposição ao masculino para ter significação (BUTLER, 2015). E a distinção entre sexo/gênero ocorreria da mesma forma, ou seja: a partir de um feminino biológico, haveria que se construir um feminino (gênero) subordinado e em consonância com o sexo.

Assim, tem-se que o sexo é fundamentado a partir da biologia e o gênero tem sua fundamentação a partir da construção social/cultural. Seguindo esse pensamento, sexo, gênero e orientação sexual são interpretados de maneiras correlacionadas e dependentes.

Tal perspectiva não deixa espaço para interpretação de gênero de forma fluida e não estanque. Sendo assim, os parlamentares evangélicos, na grande maioria, ao falarem a partir da religião - sistema que ajuda a produzir e reproduzir as assimetrias entre os gêneros - falam a partir e a favor de uma sociedade androcêntrica, com valores heteronormativos e normatizadores dos corpos.

\section{REFERÊNCIAS}

INTERAÇÕES, Belo HORIZONTE, BRASIL, V.12 N.22, P. 323-342, AGo./DEZ. 2017 
BELLOTTI, Karina Kosicki. Delas é o reino dos céus: mídia evangélica infantil na cultura pós-moderna do Brasil (anos 1950 - 2000). São Paulo: Annablume: Fapesp, 2010.

BUTLER, Judith. Como os corpos se tornam matéria. ESTUDOS FEMINISTAS, ano 10, p. 155-167, 2002. Disponível em: <https://periodicos.ufsc.br/index.php/ref/ article/view/So104-026X2002000100009>. Acesso em: 27 out.2017.

BUTLER, Judith. Performatividad, precariedad y políticas sexuales. Revista de Antropologia Iberoamericana, v. 3, n. 4, p. 321-336, 2015. Disponível em: < http://www.aibr.org/OJ/index.php/aibr/article/view/78>. Acesso em: 27 out.2017.

BRASIL, Câmara dos Deputados. Estatuto da Frente Parlamentar Evangélica. Disponível em:< http://www.camara.leg.br/internet/deputado/ Frente _ Parlamentar/53658-integra.pdf>. Acesso em: 17 ago. 2016.

BRASIL, Câmara dos Deputados. Estatuto da Frente Parlamentar Evangélica. Disponível em: <http://www.camara.leg.br/internet/deputado/Frente_Parlamentar/ 53466-integra.pdf>. Acesso em: 17 ago. 2016b.

CAMPOS, Leonildo Silveira. Os mapas, atores e números da diversidade religiosa cristã brasileira: católicos e evangélicos entre 1940 e 2007. Revista de Estudos da religião, 2008. Disponível em: <http://www.pucsp.br/rever/rv42008/t_campos. pdf > . Acesso em: 11 ago. 2013.

CAMPOS, Roberta Bivar Carneiro; et. al. A disputa pela laicidade: uma análise das interações discursivas entre Jean Wyllys e Silas Malafaia. Religião e Sociedade, p. 02-16, 2015.

Correio24Horas. Projeto de lei poderá criar o "bolsa-estupro" para evitar que mulheres abortem. Disponível em:< http://www.correio24horas.com.br/detalhe/brasil/noticia/projeto-de-lei-podera-criar-obolsa-estupro-para-evitar-que-mulheres-abortem/?cHash=49423co2fc819 e4a97ba5a52773dfd1f $>$. Acesso em: 17 ago. 2016.

FONTELES, Heinrich Araújo. A ascensão da mídia evangélica - uma (mútua) interferência política, econômica e tecnológica. Disponível em: <http://www. ufrgs. $\mathrm{br} / \mathrm{alcar} /$ encontros-nacionais-1/encontros-nacionais/6o-encontro-20081/A\%20ascensao\%20da\%20midia\%20evangelica\%202013\%20uma\%20-utua\%20interferencia\%20politica.pdf>. Acesso em: 04 out. 2017.

FRESTON, Paul. Protestantes e política no Brasil: da constituinte ao impeachment. Campinas. 1993. 303 f. Tese (Doutorado). Instituto de Filosofia e Ciências Humanas, Universidade Estadual de Campinas, Campinas, 1993. Disponível em: < http://repositorio.unicamp.br/jspui/handle/REPOSIP/279821>. Acesso em 27 out. 2017.

\section{A GAZETA DO ACRE. Deputados evangélicos radicalizam contra união de}

homossexuais na Aleac. Disponível em: < http://agazetadoacre.com/noticias/ deputados-evangelicos-radicalizam-contra-uniao-de-homossexuais-na-aleac-2/>. Acesso em: 17 ago. 2016.

GOMES, Angela de Castro. Ideologia e trabalho no estado novo. In: PANDOLFI, Dulce (org.). Repensando o Estado Novo. Rio de Janeiro: FGV, 1999.

GOMES, Edilaine Campos. Resistências e possibilidades de diálogo: sobre aborto e reações político-religiosas. 2008. Disponível em: <http://www.clam. 
org.br/uploads/arquivo/Notas_sobre_aborto_e_rea\%C3\%A7\%C3\%B5es.pdf $>$. Acesso em: 17 ago. 2016.

MACHADO, Maria das Dores Campos. Religião e Política no Brasil Contemporâneo: uma análise dos pentecostais e carismáticos católicos. Religião e Sociedade, v. 35, n. 2, 2015.

MALTA, Magno. Cristãos criam força tarefa para combater ideologia de gênero nas escolas. Disponível em: < http://www.magnomalta.com/portal2/ index.php/outrasnotas-mainmenu-45/3312-cristaos-criam-forca-tarefa-para-combater-ideologia-de-generonas-escolas >. Acesso em: 17 ago. 2016.

MARIANO, Ricardo. Neopentecostais: sociologia do novo pentecostalismo no Brasil. 4. ed. São Paulo: Edições Loyola, 2012.

MARIZ, Cecília L; GRACIANO JR, Paulo. As igrejas pentecostais no Censo de 2010. In: TEIXEIRA, Faustino. Religiões em movimento: o censo de 2010. Petrópolis: Vozes, 2013.

ONEBerto. 10 frases polêmicas ditas pelo deputado Marco Feliciano. 13/03/2013. Disponível em: < http://obutecodanet.ig.com.br/index.php/2013/ 03/13/ 10-frasespolemicas-ditas-pelo-deputado-marco-feliciano/>. Acesso em: 17 ago. 2016.

ORO, Ari; JÚNIOR, Érico Tavares de Carvalho. Eleições Gerais de 2014: Religião e Política no Rio Grande do Sul. Debates do NER, n. 18, 2010.

PIERRUCCI, Antonio Flávio. Representantes de Deus em Brasília: a bancada evangélica na Constituinte. Ciências Sociais Hoje, p. 104-132, 1989.

UNIVERSIDADE METODISTA DE SÃO PAULO. Escola de Teologia. Eleições, Igreja e religião: artigo da professora Magali Cunha. Disponível em:

<http://portal.metodista.br/fateo /noticias/eleicoes-igreja-e-religiao-entrevista-com-aprofessora-magali-cunha>. Acesso em: 17 ago. 2016.

ROCHA, Daniel. Venha a nós o vosso reino: rupturas e permanências nas relações entre escatologia e política no pentecostalismo brasileiro. 2009. 146 f. Dissertação (Mestrado) Programa de Pós-graduação em Ciências da Religião, Pontifícia Universidade Católica de Minas Gerais, Belo Horizonte, 2009. Disponível em:<

http://www1.pucminas.br/documentos/dissertacoes_ppgcr_daniel_rocha. pdf $>$. Acesso em: 27 out. 2017.

SANT'ANA, Raquel. O som da Marcha: evangélicos e espaço público na Marcha para Jesus. Religiões e Sociedade, p. 210-231, 2014. Disponível em:<http://www. scielo.br/pdf/rs/v34n2/0100-8587-rs-34-02-0210.pdf>. Acesso em: 27 out. 2017.

SOUZA, Sandra Duarte de. Mulheres evangélicas na política: tensionamentos e público e privado. Horizonte, v. 13, n. 19, 2015. Disponível em:<http://periodicos.

pucminas.br/index.php/horizonte/article/view/P.2175-5841.2015v13n39p1261>. Acesso em: 27 out. 2017.

SOUZA, Sandra Duarte de. Política religiosa e religião política: os evangélicos e o uso político do sexo. Estudos de Religião, v. 27, n. 1, p. 177-201, jan./jun. 2013. 
TADVALD, Marcelo. A reinvenção do conservadorismo: os evangélicos e as eleições federais de 2014. Debates do NER, n. 27, p. 259-288, 2015. Disponível em: < http:

//seer.ufrgs.br/index.php/debatesdoner/article/view/56482>. Acesso em: 27 out. 2017.

Recebido em 20/o3/2017 Aprovado em 02/10/2017 